\title{
Successful aging in Spanish older adults: the role of psychosocial resources
}

\author{
Cristina G. Dumitrache, ${ }^{1}$ Laura Rubio ${ }^{1}$ and Eulogio Cordón-Pozo ${ }^{2}$ \\ ${ }^{1}$ Department of Developmental and Educational Psychology, University of Granada, Granada, Spain \\ ${ }^{2}$ Department of Business and Management, University of Granada, Granada, Spain
}

ABSTRACT

Background: Psychological and social resources such as extraversion, optimism, social support, or social networks contribute to adaptation and to successful aging. Building on assumptions derived from successful aging and from the developmental adaptation models, this study aims to analyze the joint impact of different psychosocial resources, such as personality, social relations, health, and socio-demographic characteristics on life satisfaction in a group of people aged 65 years-old and older from Spain.

Method: A cross-sectional survey using non-proportional quota sampling was carried out. The sample comprised 406 community-dwelling older adults $(M=74.88, \mathrm{SD}=6.75)$. In order to collect the data, face-to-face interviews were individually conducted. A structural equation model (SEM) was carried out using the PLS software.

Results: The results of the SEM model showed that, within this sample, psychosocial variables explain $47.4 \%$ of the variance in life satisfaction. Social relations and personality, specifically optimism, were strongly related with life satisfaction, while health status and socio-demographic characteristics were modestly associated with life satisfaction.

Conclusions: Findings support the view that psychosocial resources are important for successful aging and therefore should be included in successful aging models. Furthermore, interventions aimed at fostering successful aging should take into account the role of psychosocial variables.

Key words: successful aging, life satisfaction, resources, social relations, personality

\section{Introduction}

Successful aging is a multidimensional process characterized by the maintenance of cognitive and physical functioning, the absence of disability, and an active engagement in social and productive activities (Rowe and Khan, 1997). While the successful aging model by Rowe and Khan (1997) shows that physical health and functional ability maintenance are crucial (Zarit, 2009; Jopp et al., 2015), the majority of older people have to deal with chronic health conditions and functional impairment, and despite them, they are still able to engage in social and productive activities (Zarit, 2009) and describe themselves as being successful in their aging process. In

Correspondence should be addressed to: Cristina G. Dumitrache, Department of Developmental and Educational Psychology, University of Granada, Campus de Cartuja S/N, 18071, Granada, Spain. Phone: 00349582419 58. Email: cgdumitrache@ugr.es. Received 26 Jul 2017; revision requested 26 Aug 2017; revised version received 20 Dec 2017; accepted 12 Feb 2018. First published online 25 May 2018. addition, several researchers consider that optimal development can be measured by using a series of criteria such as a good health, social engagement, and a positive assessment of life (Huxhold et al., 2013). Among the most used outcomes that reflect successful aging, Cosco et al. (2014) identified in a systematic review the following ones: physiological status (that includes health, functional status, or longevity), well-being (affect and life satisfaction), active engagement with life (social support systems and social interaction), personal resources (coping and resilience), and extrinsic factors (environment and economic status).

With regards to all these criteria, as emphasized by Caprara (2008), criteria and predictors of successful aging are often misunderstood, sometimes predictors are used as criteria and other times they are not. Consequently, life satisfaction can be considered an important outcome associated with successful aging and an essential element of the subjective dimension of aging (IMSERSO, 2009; Bowling and Dieppe, 2005). Life satisfaction is as 
relevant as a successful aging criterion as objectives ones, such as health status or cognitive functioning (Blazer, 2006). Furthermore, according to some authors, it is one of the most important criteria for successful aging (e.g. Kanning and Schlicht, 2008).

In this way, the successful aging model by Rowe and Khan (1997) might be incomplete by not only including life satisfaction as subjective criterion of successful aging, but it also does not explain how individuals maintain life satisfaction despite difficulties such as health impairment. In order to explain why some older adults are satisfied with their lives and age successfully, despite health and functional impairment, an approach that contemplates adaptation and a life-course perspective should be taken (Rowe and Kahn, 2015).

An approach that adopts a life-course perspective is the model of developmental adaptation (Martin and Martin, 2002). This model postulates that past and present negative experiences could affect older people's life satisfaction and adaptation ability (Martin and Martin, 2002). According to this model, successful aging and adaptation are possible due to the existence of present and past psychological and socioeconomic resources (Martin and Martin, 2002). These psychological resources, or internal resources, include personality characteristics, self-efficacy or control beliefs, and socioeconomic, or external resources, involve different types of perceived social support, social networks, and financial status. These resources mitigate the effect of detrimental experiences or developmental changes such as health and functional status impairment, which are potentially stressful circumstances that can negatively impact older individuals' well-being, mental, and physical health (Martin and Martin, 2002).

In the model of developmental adaptation, health is considered a developmental outcome, a consequence of adaptation, and a possible stressful circumstance if it is impaired (Martin and Martin, 2002). Suffering from a higher number of illnesses, having an impaired functional status, or a negative health perception are associated with a decrease in life satisfaction (Bishop et al., 2006; Cacioppo et al., 2008; Robb et al., 2008; Gwozdz and Sousa-Poza, 2010; Enkvist et al., 2012). However, despite health-related changes, the elderly who have certain personality dispositions and count on social support, or have economic resources, are more likely to be satisfied with their lives and age successfully (Martin and Martin, 2002).

Social relations are important correlates for successful aging (Martin and Martin, 2002; Litwin and Shiovitz-Ezra, 2006; Litwin and Stoeckel, 2013). Both researchers and older people themselves have identified social relations as the most important condition for well-being (von Faber et al., 2001). In addition, many of the studies on life satisfaction and social relationships corroborate this positive association (Chan and Lee, 2006; Hsu and Tung, 2010; Litwin and Stoeckel, 2013) and emphasize the relevance of subjective aspects of social relations like satisfaction with the components of the network and satisfaction with frequency of contact or perceived social support (Borg et al., 2006; Litwin and Shiovitz-Ezra, 2006; Cacioppo et al., 2008; Berg et al., 2009). Nevertheless, the subjective aspects of social relations and other social factors, such as gender or socioeconomic status, are not included in the successful aging model by Rowe and Kahn (Rowe and Kahn, 1997, 2015).

In relation to economic resources, some studies have shown that they also are relevant for life satisfaction and for successful aging. These factors influence older adults' perceptions on their aging process, their physical and mental health, and leisure and professional trajectories (Bishop et al., 2006; Gouda and Okamoto, 2012). However, of all economic-related variables only satisfaction with income has been identified as an important predictor of older adults' life satisfaction (Berg et al., 2009; Hsu, 2012).

Finally, personality characteristics are key resources contributing to adaptation, healthy ageing, and well-being (Woods and Windle, 2008). Moreover, personality dispositions are strongly correlated with life satisfaction (Heo and Lee, 2010; Herero and Extremera, 2010; Ní Mhaoláin et al., 2012) and explain life satisfaction stability across lifespan (Ozer and Benet-Martínez, 2006). It has been suggested that some dispositions are linked to well-being more strongly than others. Among all personality characteristics, extraversion has been identified as one of the traits that more strongly correlate with life satisfaction (Lucas and Fujita, 2000; Hofer et al., 2008). Another personality trait that is strongly linked to life satisfaction is optimism, a highly beneficial trait (Caprara, 2008) that acts as a defense against strain and contributes to resilience (Heo and Lee, 2010; Herero and Extremera, 2010; Baldwin et al., 2011; Ju et al., 2013).

There is a wide scientific evidence on the resources that foster adaptation in the aging and the psychological literature (e.g. Bishop et al., 2006; Schöllgen et al., 2011; Windsor et al., 2012; Dai et al., 2013; Cho et al., 2015). Nevertheless, some of these resources are not included in the original model by Rowe and Kahn $(1997,2015)$ and more evidence on the factors related to well-being as a result of successful aging are needed. What is more, the impact that personality has on life satisfaction and on affective well-being is moderated by cultural 
factors (Schimmack et al., 2002). Similarly, the way exchanges of social support are perceived and relevance of quality of social interaction in predicting life satisfaction vary by cultural context (Kang et al., 2003), but a few studies on this issue have been carried out with Spanish older people. Thus, we believe it would be informative to study the impact of psychosocial resources on the Spanish older adults' life satisfaction in order to better understand how these variables influence their experience of aging successfully. Therefore, the aim of this study was to analyze the joint impact of different psychosocial resources, such as personality, social relations, health, and sociodemographic characteristics on life satisfaction in a group of people aged 65 years-old and older from Spain.

\section{Methods}

\section{Participants}

In this cross-sectional survey, the sample comprised 406 community-dwelling older adults $(62.1 \%$ women) aged between 65 and 99 years $\left(M_{\text {age }}=74.88\right.$, $\mathrm{SD}=6.75$ ) who attended senior activity centers or belonged to elderly associations and lived in urban areas of Granada, southern Spain. The participants had a relatively low educational status (18\% had no formal education although they could read and write, $33 \%$ had primary education, $27 \%$ had secondary education, and $20 \%$ had university education). More than half of the participants had a partner or were married (51\%), while $39.2 \%$ were widowed, $5.9 \%$ were divorced or separated, and $3.9 \%$ were single. Furthermore, $62 \%$ of the participants were cohabiting, while $38 \%$ were living alone.

\section{Measures}

Overall life satisfaction was measured using the Spanish version of the Satisfaction with Life Scale (Diener et al., 1985) that has been previously validated with older adults (Pons et al., 2000). In this version, the five items (e.g. "In most ways my life is close to my ideal") are rated on a five-point Likert scale $(1=$ strongly disagree to $5=$ strongly agree) and form a unique factor that shows good internal consistency (in the present study Cronbach's $\alpha$ [CA] was 0.81 ).

\section{Personal resources}

Extraversion was assessed using the Spanish version of the Extraversion Scale, which was extracted from the NEO-Five Factor Inventory (Costa and McCrae, 1999). This is a 12 -item instrument (e.g.
"I really enjoy talking to people") that is rated on a five-point scale $(0=$ strongly disagree to $4=$ strongly agree; $\alpha=0.82$ ).

Optimism was measured using the Spanish version of the Revised Life Orientation Test (LOTR) (Scheier et al., 1994; Otero et al., 1998). This instrument consists of 10 items; six of them measure optimism/pessimism (e.g. "In uncertain times, I usually expect the best") and four are filler items. Each item was rated on a five-point scale $(0=$ strongly disagree to $4=$ strongly agree, $\alpha=0.70)$.

\section{Social resources}

Social network size was obtained by summing up answers with regards to the number of family members, friends, close friends, and other people who participants mentioned they had contact with.

Time spent in the company of friends and family was evaluated by two questions: "How many weekly hours do you spend in the company of your friends?" and "How many weekly hours do you spend in the company of your close family members who you do not cohabitate with?"

Social Support was measured using the Spanish version of the Medical Outcomes Study Social Support Survey Instrument (MOS), which was validated with older people (Sherbourne and Stewart, 1991; Revilla-Ahumada et al., 2005). This is a 20 -item instrument (e.g. "Someone you can count on to listen to you when you need to talk") that is rated using a five-point Likert scale $(1=$ none of the time to $5=$ all of the time; $\alpha=0.97)$.

Satisfaction with family was measured using a single item: "How satisfied are you with your family members?" Participants indicated how satisfied they were with their family members using a tenpoint scale $(1=$ very dissatisfied; $10=$ very satisfied).

Satisfaction with friends was measured using a single item: "How satisfied are you with your friends?" Participants indicated how satisfied they were with their friends using a ten-point scale ( $1=$ very dissatisfied; $10=$ very satisfied $)$.

Socioeconomic resources were measured by one question: "How satisfied are you with your current income?" ( $1=$ very unsatisfied; $10=$ very satisfied).

Health impairment was assessed by asking the participants to indicate whether they had any restrictions in performing activities due to health problems ("Do any of your illnesses restrict your activities?" $1=$ no illness or no restriction due to illness; 2 = restriction due to illness). Also, perceived health was assessed using one item (How 
do you rate your current state of health?) that was rated on a three-point scale $(1=$ very bad or bad, $2=$ regular, $3=$ very good or good).

Socio-demographic characteristics were assessed using a structured interview designed for this study that included questions on age, gender $(1=$ male; $2=$ female $)$, marital status $(1=$ single; $2=$ married or with partner; $3=$ widowed; $4=$ divorced or separated), educational status $(1=$ no formal education but reads and writes; $2=$ primary education; $3=$ secondary education; $4=$ university education), and living arrangements $(1=$ living alone; 2 = cohabiting).

\section{Procedure}

\section{Sampling and data collection procedure}

The sample was selected using a non-proportional quota sampling. The sample size was calculated at a $95 \%$ confidence level based on the population of people aged between 65 and 99 years living in urban areas of Granada. In order to guarantee sufficient sampling of men and participants aged $80+$, a minimum number of interviews were established for men and women by age subgroups (65-69; 70-74; 75-79; 80-84; 85-89; 90-94; 95-99) proportionate to age groups by gender in the population of older people in the study area. The inclusion criteria to take part in this study were to be aged 65 years or older and live in the community. Face-to-face interviews were individually conducted with older adults who volunteered to participate in the study. After providing information about the study (the purpose, the expected duration of the interview, and the procedures) the informed consent form was signed. The interviewer read each question aloud and recorded the participant's answer on the answer sheet; participants had showcards with the answer options for each scale.

\section{Data analysis procedure}

To estimate the model shown in Figure 1, the partial least squares or PLS technique was used and the analyses were performed using the SmartPLS 3 software (Ringle et al., 2015). This analysis is a type of structural equation models (SEM) that use an approach based on components. In comparison to other software, such as LISREL or Mplus, that also allow SEM and are based on the covariance, the PLS technique is mainly orientated at predictive causal analysis and it is based on the variance. The PLS technique is adequate for this research because it is mainly useful for exploratory predictive research that is not aimed at finding evidence for causal relationships (Chin, 1998). Furthermore, the conceptual basis on which are based some of the hypotheses that need to be contrasted in this research are not fully developed; thus, the PLS technique is especially suitable in these cases (Chin, 1998). Since the PLS-SEM technique does not assume normal distribution of the sample, in order to determine the statistical significance of the estimated parameters, the non-parametric bootstrap procedure was used (Davison and Hinkley, 1997). Due to it, following recommendation by Hair et al. (2017), 5.000 bootstrap samples were used with 1.000 cases per sample.

\section{Results}

\section{Validity and reliability of the measurement scales}

Table 1 shows means, standard deviation, minimum and maximum levels of the continuous variables, and frequency for dichotomous variables included in the analysis.

Before estimating the model, the validity and reliability of the measurement scales used in the proposed model have to be evaluated. With respect to the reliability of the scales, recommendations by Hair et al. (2017) were followed. The CA, the construct reliability (CR), and the average variance extracted (AVE) were calculated. For the CA, although a minimum value of 0.7 is usually required for good reliability (Peterson, 1994), a value of 0.6 is acceptable for the exploratory studies (Robinson et al., 1991; Peterson, 1994). The minimum values required for the CR and the AVE indicators are 0.7 and 0.5, respectively (Fornell and Larcker, 1981; Hair et al., 2017). On the other hand, following the literature recommendation (Hair et al., 2017), the standardized loadings have to be higher than 0.5 and ideally of at least 0.7 , and statistically significant, to indicate good convergent validity of the items that measure the different constructs (Hair et al., 2017). Therefore, the items that did not meet the criteria were removed from the analysis. In this way, only five of the items that measure extraversion were included in the analyses. Similarly, only four items of the six items that measure optimism were included in the analyses. Finally, 15 of the 19 social support items were considered. Table 2 shows the items of each scale that were included in this study and the results of validity and reliability tests we performed. As can be seen in Table 2, all the measurement scales were valid and reliable.

In order to determine the discriminant validity, we followed the criteria suggested by Fornell 


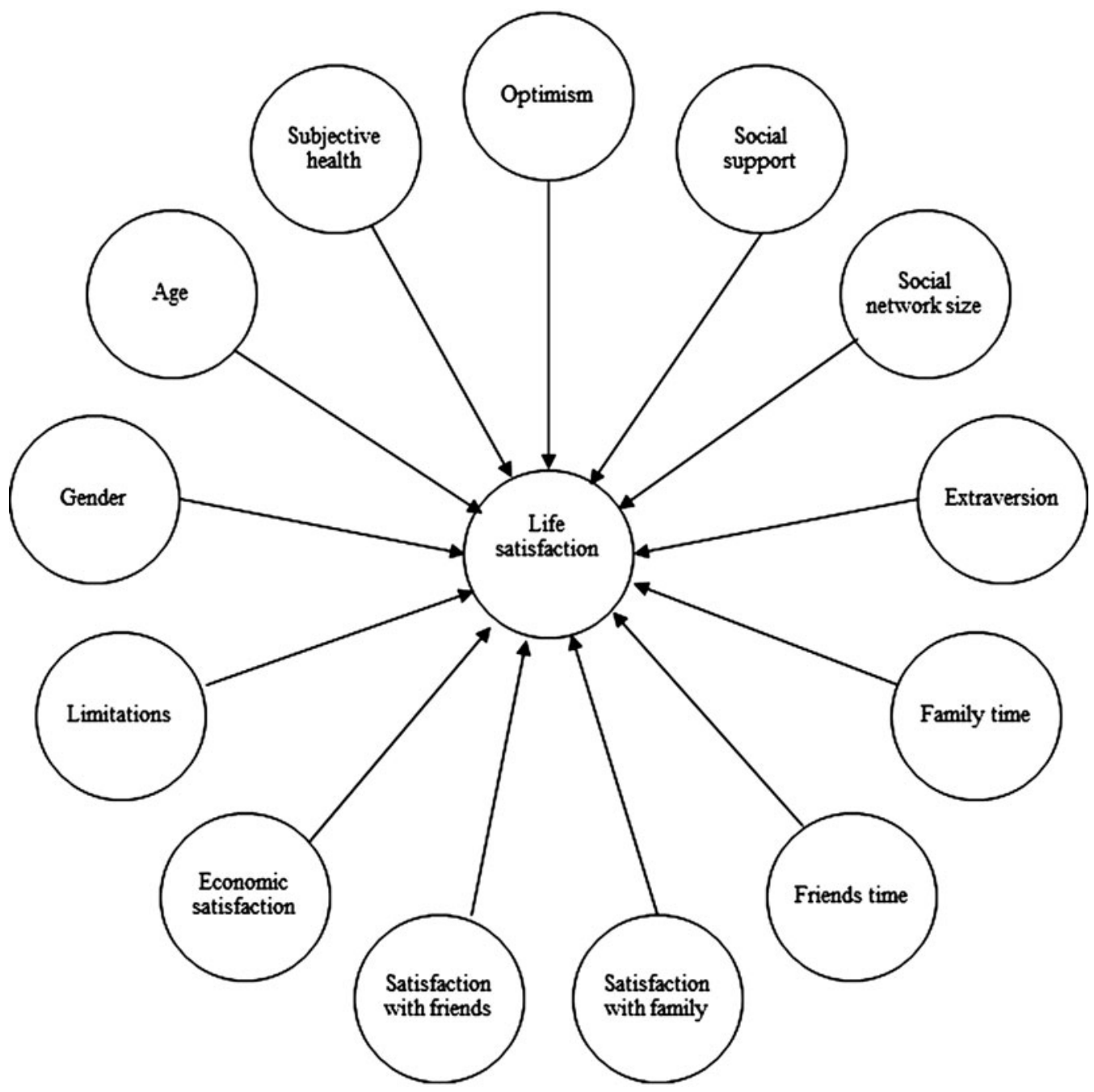

Figure 1. General model to be tested.

and Larcker (1981), according to whom good discriminant validity can be assumed when the AVE indicator of each construct is higher than the shared variance with any other construct. As it can be seen in Table 3, the values of the AVE for each one of the constructs - that are presented on a diagonal have higher values that the rest of the boxes; thus, the constructs measured in this study have good discriminant validity.

\section{Analysis of the proposed model}

After the validity and reliability of the measurement scales were verified, the structural model analysis was performed. As shown in Figure 2, the proposed model explained $47.4 \%$ of the variance in life satisfaction. Seven of the thirteen hypothesized associations were found significant at least at 95\%. Those variables were age, personal resources as optimism and extraversion, social support, satisfaction with family, time spent with family, and satisfaction with economic resources. Also, another five associations were marginally significant, including gender, social network size, satisfaction with friends, functional limitations, and subjective health.

Likewise, of all the analyzed relationships, only functional limitations was negatively related with life satisfaction, while the other variables were all positively associated with life satisfaction. Finally, only the time spend with friends was not related with life satisfaction.

\section{Discussion}

The aim of this study was to analyze the joint impact of different psychosocial resources, such as personality, social relations, health, and sociodemographic characteristics on life satisfaction in a group of people aged 65 years-old and older from Spain. A significant, novel contribution of this study is that it provides an understanding of how Spanish older adults manage to age 
Table 1. Descriptive statistics of the study variables

\begin{tabular}{|c|c|c|c|c|}
\hline QUANTITATIVE VARIABLES & MEAN & SD & MINIMUM & MAXIMUM \\
\hline \multicolumn{5}{|l|}{ Personal resources } \\
\hline Extraversion & 2.34 & 0.73 & 0.58 & 4 \\
\hline Optimism & 2.80 & 0.72 & 0 & 4 \\
\hline \multicolumn{5}{|l|}{ Social resources } \\
\hline Social network size & 86.77 & 43.56 & 9 & 281 \\
\hline Friends time & 10.64 & 11.08 & 0 & 70 \\
\hline Family time & 12.41 & 14.54 & 0 & 85 \\
\hline Social support & 83.35 & 12.77 & 1.26 & 5 \\
\hline Satisfaction friends & 8.26 & 1.80 & 1 & 10 \\
\hline Satisfaction family & 8.71 & 1.92 & 1 & 10 \\
\hline \multicolumn{5}{|l|}{ Socioeconomic resources } \\
\hline Economic satisfaction & 7.86 & 2.13 & 1 & 10 \\
\hline \multicolumn{5}{|l|}{ Health impairment } \\
\hline Subjective health & 2.43 & 0.67 & 1 & 3 \\
\hline \multicolumn{5}{|l|}{ Socio-demograp. charact. } \\
\hline Age & 74.88 & 6.75 & 65 & 99 \\
\hline Overall life satisfaction & 3.84 & 0.77 & 1.20 & 5 \\
\hline \multicolumn{5}{|l|}{ Categorical variables } \\
\hline Health impairment & \multicolumn{2}{|c|}{ Yes } & \multicolumn{2}{|c|}{ No } \\
\hline Limitations & \multicolumn{2}{|c|}{52.7} & \multicolumn{2}{|c|}{47.3} \\
\hline Socio-demograp. charact. & \multicolumn{2}{|c|}{ Men } & \multicolumn{2}{|c|}{ Women } \\
\hline Gender & \multicolumn{2}{|c|}{37.9} & \multicolumn{2}{|c|}{62.1} \\
\hline
\end{tabular}

Table 2. Validity and reliability coefficients of the measurements scales

\begin{tabular}{|c|c|c|c|c|c|c|}
\hline CONSTRUCT & ITEMS & $\begin{array}{l}\text { STANDARDIZED } \\
\text { LOADINGS }\end{array}$ & T-VALUE & $A V E$ & CR & $\mathrm{AC}$ \\
\hline \multirow[t]{5}{*}{ Extraversion } & EX1 & 0.812 & $32.653^{* *}$ & 0.526 & 0.845 & 0.792 \\
\hline & $\mathrm{EX} 2$ & 0.587 & $11.356^{* *}$ & & & \\
\hline & EX4 & 0.804 & $26.545^{* *}$ & & & \\
\hline & EX6 & 0.672 & $14.840^{* *}$ & & & \\
\hline & EX10 & 0.727 & $22.076^{* *}$ & & & \\
\hline \multirow[t]{4}{*}{ Optimism } & OP1 & 0.699 & $14.286^{* *}$ & 0.530 & 0.818 & 0.704 \\
\hline & OP4 & 0.755 & $21.932^{* *}$ & & & \\
\hline & OP9 & 0.677 & $15.224^{* *}$ & & & \\
\hline & OP10 & 0.777 & $22.823^{* *}$ & & & \\
\hline \multirow[t]{15}{*}{ Social support } & SS3 & 0.745 & $19.585^{* *}$ & 0.524 & 0.943 & 0.935 \\
\hline & SS4 & 0.721 & $15.333^{* *}$ & & & \\
\hline & SS6 & 0.655 & $17.169^{* *}$ & & & \\
\hline & SS7 & 0.708 & $23.600^{* *}$ & & & \\
\hline & SS8 & 0.740 & $17.228^{* *}$ & & & \\
\hline & SS9 & 0.774 & $22.397^{* *}$ & & & \\
\hline & SS10 & 0.710 & $22.174^{* *}$ & & & \\
\hline & SS11 & 0.749 & $26.703^{* *}$ & & & \\
\hline & SS13 & 0.763 & $18.081^{* *}$ & & & \\
\hline & SS14 & 0.690 & $20.123^{* *}$ & & & \\
\hline & SS16 & 0.779 & $21.669^{* *}$ & & & \\
\hline & SS17 & 0.759 & $19.171^{* *}$ & & & \\
\hline & SS18 & 0.698 & $20.788^{* *}$ & & & \\
\hline & SS19 & 0.666 & $17.635^{* *}$ & & & \\
\hline & SS20 & 0.692 & $18.349^{* *}$ & & & \\
\hline \multirow[t]{5}{*}{ Life satisfaction } & LS1 & 0.810 & $39.294^{* *}$ & 0.557 & 0.862 & 0.800 \\
\hline & LS2 & 0.714 & $19.395^{* *}$ & & & \\
\hline & LS3 & 0.814 & 38.516 & & & \\
\hline & LS4 & 0.707 & 21.108 & & & \\
\hline & LS5 & 0.674 & 16.932 & & & \\
\hline
\end{tabular}

Note: $\mathrm{N}=406 .{ }^{* *} \mathrm{~T}$-Values were significant at $\mathrm{p}<.01$. 
Table 3. Discriminant validity of the measurement scales

\begin{tabular}{|c|c|c|c|c|c|c|}
\hline & $M$ & $S D$ & 1 & 2 & 3 & 4 \\
\hline 1. Extraversion & 2.34 & 0.73 & 0.526 & 0.176 & 0.066 & 0.094 \\
\hline 2. Optimism & 2.80 & 0.72 & $0.420^{* *}$ & 0.530 & 0.131 & 0.192 \\
\hline 3. Social support & 83.35 & 12.77 & $0.257^{* *}$ & $0.363^{* *}$ & 0.524 & 0.198 \\
\hline 4. Life satisfaction & 3.84 & 0.77 & $0.308^{* *}$ & $0.439^{* *}$ & $0.446^{* *}$ & 0.557 \\
\hline
\end{tabular}

Note: On the diagonal, the average variance extracted (AVE) is presented; under the diagonal, correlations among variables are presented; and on top of the diagonal, the shared variances (squared correlations) are presented. $M$ : mean; SD: standard deviation. ${ }^{* *} \mathrm{p}<0.01$

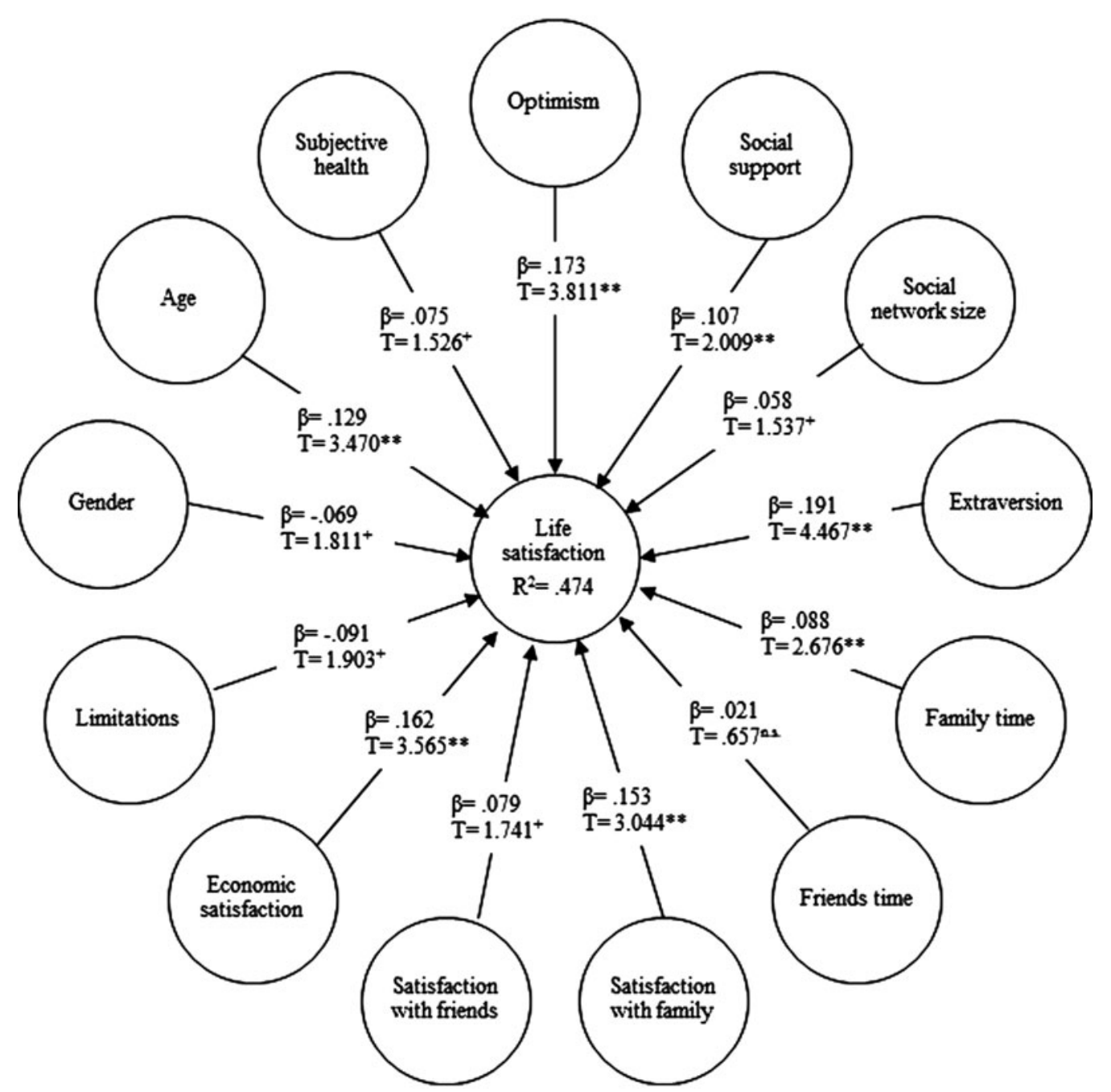

Figure 2. Standardized coefficients for the estimated structural model. $\beta$ : standardized coefficients; $T$ : $t$-values; ${ }^{* *} p<0.05 ;{ }^{+} p<0.10$; n.s.: not significant.

successfully. Results suggest that, of all resources we included in the model, high levels of personal resources such as optimism and extraversion and social resources such as counting on a wide social network, feeling satisfied with family and friends, and spending more time with family members explain the variance in life satisfaction together with age, gender (being a women), having a positive perception of one's health, and being satisfied with one's income. Meanwhile, as expected, having functional impairment was negatively linked to life satisfaction. The only variable that was not linked to participants' life satisfaction was the time spent in company of friends. The proposed model, which included personal, socioeconomic resources, and health, explained a considerable amount of the variance in life satisfaction, namely a $47.4 \%$. Thus, it seems that these factors are relevant in explaining 
Spanish older adults' ability to adapt to the aging process and for their life satisfaction.

The results from this study are in agreement with findings from previous studies carried out in other cultural contexts (e.g. Bishop et al., 2006; Schöllgen et al., 2011; Windsor et al., 2012; Dai et al., 2013; Cho et al., 2015). At the same time, this study provides evidence for the model of developmental adaptation (Martin and Martin, 2002), which postulates that social, economic, and personal resources such as personality, coping strategies or locus of control (Martin and Martin, 2002) constitute important predictors of successful aging and adaptation to the aging process as well as relevant determinants of older adults' life satisfaction.

In the first place, personal resources evaluated in this research, optimism and extraversion, were the factors with the highest direct effect on older adults' life satisfaction. This is in agreement with results from previous studies (Hofer et al., 2008; Heo and Lee, 2010; Herero and Extremera, 2010; Baldwin et al., 2011; Ju et al., 2013) and reiterates that these are important variables that should be included in successful aging models. Furthermore, this study extends the existing evidence in favor of the relevance of these two variables for older adults' life satisfaction and successful aging by providing data from the Spanish cultural context. This was important since a few studies on this issue have been carried out with Spanish older people.

With respect to social resources, satisfaction with family was the social factor with the largest effect on subjective well-being, followed by perceived social support and spending more time with family. On the other hand, satisfaction with friends also predicted life satisfaction, however, its effect was only marginally significant. In addition, social network size was the resource with less effect. Therefore, in this research, both social objectives and subjective resources were relevant predictors of successful aging and life satisfaction. Nevertheless, subjective aspects of social relations, such as satisfaction with family and perceived social support, seem to have a larger direct effect on life satisfaction compared to objective aspects of social resources such as network size and time spent with family members, which is in agreement with previous studies (Borg et al., 2006; Litwin and Shiovitz-Ezra, 2006; Cacioppo et al., 2008; Berg et al., 2009). It is also important to emphasize that satisfaction with family was the main social resource influencing older adult's life satisfaction. In the Spanish context, older people tend to increase their dependence on family when health problems or disability arise, so it is not surprising that from all social resources, relationships with family are the main influence on subjective well-being of older people. Because how exchanges of social support are perceived and relevance of quality of social interaction in predicting life satisfaction vary by cultural context (Kang et al., 2003), this result might not be applicable to other cultural contexts. It is possible that in other cultural contexts, variables such as satisfaction with friends might be as important for older adults' life satisfaction as satisfaction with family.

Apart from the social factors described earlier, satisfaction with income was also included in the model. Economic resources can influence successful aging, although generally they are not included in the traditional models of successful aging (Rowe and Kahn, 1997). In this research, satisfaction with income was a relevant predictor of life satisfaction, which is also in agreement with previous studies (Berg et al., 2009; Hsu, 2012). In addition, this economic factor had a larger effect on life satisfaction than other subjective or objectives social resources mentioned above. However, results indicate that, contrary to the successful aging model recently made by Rowe and Kahn (2015), the variable that should be included in the model of successful aging is not the socioeconomic status per se but satisfaction with income. This result reiterates that what matters for older people's life satisfaction is the subjective evaluation of their resources and not having a higher objective income.

Besides Rowe and Kahn (2015) proposed that other social factor to be included in the model of successful aging is gender. Despite the fact that gender and age are both variables that have been traditionally studied in gerontological studies, they have not been included in the majority of models studying successful aging. In this study, it was found that women and the older participants had a higher life satisfaction, although the effect of gender was smaller than the effect of age and only marginally significant. However, these results support the importance of adopting a gender and life-course perspective when analyzing successful aging.

Finally, with regards to health status, in the successful aging model by Rowe and Kahn (1997), physical health and functional ability maintenance are crucial (Zarit, 2009; Jopp et al., 2015), meanwhile the model of developmental adaptation (Martin and Martin, 2002) postulates that health status is a developmental outcome, which, if impaired, can constitute a possible stressful circumstance (Martin and Martin, 2002). Results from this study show that health status is linked to older adults' life satisfaction, in particular functional limitations and a negative self-health perception have a deleterious impact on older 
adults' life satisfaction, although the effect was only marginally significant. This finding is in agreement with previous studies (Bishop et al., 2006; Cacioppo et al., 2008; Robb et al., 2008; Gwozdz and Sousa-Poza, 2010; Enkvist et al., 2012) and reiterates the relevance of health-related variables for older adults' life satisfaction.

Although findings from this study produced several relevant outcomes in understanding successful aging and well-being in Spanish older adults, several limitations affect the generalization of the results of this study. The use of nonprobability sampling might not allow extrapolating the results of this study to the general Spanish population of older adults. In addition, the crosssectional design does not allow for distinguishing between predictors and outcome variables, so the analyses we conducted only had descriptive purposes and results should be received with caution. In this way, future studies should use longitudinal designs and representative samples. Also, in this study, we only explored the role of some of the resources proposed in the model of developmental adaptation (Martin and Martin, 2002). Together these variables explained $47.4 \%$ of the variance in life satisfaction. Some relevant variables, such as other personality dispositions like agreeableness, openness, and neuroticism, have not been considered. Because well-being depends on multiple mechanisms, future studies should include other protective factors such as self-efficacy or perceived control, other personality traits, and distal influences such as the patterns of social interaction through the lifespan or stressful events experienced before old age that could explain the remaining variance in life satisfaction. However, despite limitations, we believe this study is useful for advancing the knowledge on the importance of psychosocial resources for life satisfaction and successful aging and for identifying specific resources, such as optimism and social relations that can be modified in order to increase older adults' probability to age successfully. Besides, to our knowledge, this is the first study to analyze the joint impact of psychosocial variables in Spanish older adults and the model is able to predict a considerable amount of the variance in life satisfaction. Thus, this study provides evidence in favor of the model of developmental adaptation (Martin and Martin, 2002) in a different cultural context to the original cultural setting where the model was proposed. Finally, this study has important practical implications for the gerontological practice because it highlights the factors that are relevant for older adults' life satisfaction and successful aging, and this allows professionals who work with older people to design interventions to enhance older adults' probability to age successfully and to maintain well-being.

\section{Conflict of interest}

None.

\section{Description of authors' roles}

C.G. Dumitrache formulated the research questions, designed the study, supervised the data collection, and wrote most of the manuscript. L. Rubio supervised the data collection, carried out the statistical analysis, assisted with writing the paper, and edited the manuscript. E. Cordón-Pozo was responsible for the statistical design of the study and assisted with writing the paper.

\section{Acknowledgments}

We would like to thank the participants of this study for their cooperation and the committees of the senior activity centers and elderly associations whose cooperation was crucial to this research.

\section{References}

Baldwin, D. R., Jackson, D., Okoh, I. and Cannon, R. L. (2011). Resiliency and optimism: an African American senior citizen's perspective. The fournal of Black Psychology, $37,24-41$.

Berg, A. I., Hoffman, L., Hassing, L. B., McClearn, G. E. and Johansson, B. (2009). What matters, and what matters most, for change in life satisfaction in the oldest-old? A study over 6 years among individuals $80+$. Aging $\mathcal{G}$ Mental Health, 13, 191-201. doi:10.1080/13607860802342227

Bishop, A., Martin, P. and Poon, L. (2006). Happiness and congruence in older adulthood: a structural model of life satisfaction. Aging $\mathcal{E}$ Mental Health, 10, 445-453. doi:10.1080/13607860600638388

Blazer, D. G. (2006). Successful aging. American fournal of Geriatric Psychiatry, 14, 2-5. doi: 10.1097/01.JGP.0000195222.93655.d1

Borg, C., Hallberg, I. R. and Blomqvist, K. (2006). Life satisfaction among older people $(65+)$ with reduced self-care capacity: the relationship to social, health and financial aspects. Fournal of Clinical Nursing, 15, 607-618.

Bowling, A. and Dieppe, P. (2005). What is successful ageing and who should define it? British Medical fournal, 331, 1548-1551. doi:10.1136/bmj.331.7531.1548

Cacioppo, J. T., Hawley, L. C., Kalil, A., Hughes, M. E., Waite, L. and Thisted, R. A. (2008). Happiness and the invisible threads of social connection. The Chicago health, aging, and social relations study. In M. Eid and 
R. J. Larsen (eds.), The Science of Subjective Well-Being (pp. 195-219). New York: Guilford Press.

Caprara, M. (2008). Active aging promotion [La promoción del envejecimiento activo]. In R. Fernández Ballesteros (ed.), Psychology of Old Age: An Applied Psychogeriatrics [Psicología de la Vejez: Una Psicogerontología Aplicada] (pp. 337-361). Madrid: Pirámide.

Chan, Y. and Lee, R. P. (2006). Network size, social support and happiness in later life: a comparative study of Beijing and Hong Kong. Fournal of Happiness Studies, 7, 87-112.

Chin, W. W. (1998). The partial least squares to structural equation modeling. In G. A. Marcoulides (ed.), Modern Methods for Business Research (pp. 295-336). Mahwah, NJ: Lawrence Earlbaum Associates Publisher.

Cho, J., Martin, P. and Poon, L. W. (2015). Successful aging and subjective well-being among oldest-old adults. The Gerontologist, 55, 132-143.

Cosco, T. D., Prina, A. M., Perales, J., Stephan, B. and Brayne, C. (2014). Operational definitions of successful aging: a systematic review. International Psychogeriatrics, 26, 373-381. doi:10.1017/S1041610213002287

Costa, P. T. and McCrae, R. R. (1999). Inventario de Personalidad NEO Revisado (NEO PI-R) e Inventario NEO Reducido de Cinco Factores (NEO-FFI) [NEO PI-R, Revised NEO Personality Inventory and NEO Five-Factor Inventory (NEO-FFI)]. Madrid: TEA Editions.

Dai, B., Zhang, B. and Li, J. (2013). Protective factors for subjective well-being in Chinese older adults: the roles of resources and activity. Fournal of Happiness Studies, 14, 1225-1239. doi:10.1007/s10902-012-9378-7

Davison, A. C. and Hinkley, D. V. (1997). Bootstrap Methods and their Application. Cambridge, UK: Cambridge University Press.

Diener, E., Emmons, R. A., Larsen, R. J. and Griffin, S. (1985). The satisfaction with life scale. Fournal of Personality Assessment, 49, 71-75. doi:10.1207/s15327752jpa4901_13

Enkvist, A. A., Ekström, H. H. and Elmståhl, S. S. (2012). What factors affect life satisfaction (LS) among the oldest-old? Archives of Gerontology and Geriatrics, 54, 140-145.

Fornell, C. and Larcker, D. F. (1981). Evaluating structural equation models with unobservable variables and measurement error. Fournal of Marketing Research, 18, 39-50. doi: $10.2307 / 3151312$

Gouda, K. and Okamoto, R. (2012). Current status of and factors associated with social isolation in the elderly living in a rapidly aging housing estate community. Environmental Health and Preventive Medicine, 17, 500-511. doi: 10.1007/s12199-012-0282-x

Gwozdz, W. and Sousa-Poza, A. (2010). Ageing, health and life satisfaction of the oldest old: an analysis for Germany. Social Indicators Research, 97, 397-417. doi:10.1007/s11205-009-9508-8

Hair, J. F., Hult, G. T. M., Ringle, C. M. and Sarstedt, M. (2017). A Primer on Partial Least Squares Structural Equation Modeling (PLS-SEM). Thousand Oaks, CA: Sage.

Heo, J. and Lee, Y. (2010). Serious leisure, health perception, dispositional optimism, and life satisfaction among senior games participants. Educational Gerontology, 36, 112-126. doi: 10.1080/03601270903058523

Herero, V. G. and Extremera, N. (2010). Daily life activities as mediators of the relationship between personality variables and subjective well-being among older adults. Personality and Individual Differences, 49, 124-129. doi: 10.1016/j.paid.2010.03.019

Hofer, J., Busch, H. and Kiessling, F. (2008). Individual pathways to life satisfaction: the significance of traits and motives. Fournal of Happiness Studies, 9, 503-520. doi:10.1007/s10902-007-9086-x

Hsu, H. (2012). Trajectories and covariates of life satisfaction among older adults in Taiwan. Archives of Gerontology and Geriatrics, 55, 210-216. doi:10.1016/j.archger.2011.08.011

Hsu, H. and Tung, H. (2010). What makes you good and happy? effects of internal and external resources to adaptation and psychological well-being for the disabled elderly in Taiwan. Aging \& Mental Health, 14, 851-860. doi:10.1080/13607861003800997

Huxhold, O., Fiori, K. L. and Windsor, T. D. (2013). The dynamic interplay of social network characteristics, subjective well-being, and health: the costs and benefits of socio-emotional selectivity. Psychology and Aging, 28, 3-16. doi: $10.1037 / \mathrm{a} 0030170$

IMSERSO (2009). Informe 2008. Las Personas Mayores en España [Report 2008. Older People in Spain]. Madrid: Ministerio de Trabajo y Asuntos Sociales.

Jopp, D. S., Wozniak, D., Damarin, A. K., De Feo, M., Jung, S. and Jeswani, S. (2015). How could lay perspectives on successful aging complement scientific theory? Findings from a U.S. and a German life-span sample. The Gerontologist, 55, 91-106. doi:10.1093/geront/gnu059

Ju, H., Shin, J. W., Kim, C., Hyun, M. and Park, J. (2013). Mediational effect of meaning in life on the relationship between optimism and well-being in community elderly. Archives of Gerontology and Geriatrics, 56, 309-313. doi:10.1016/j.archger.2012.08.008

Kang, S., Shaver, P. R., Sue, S., Min, K. and Jing, H. (2003). Culture-specific patterns in the prediction of life satisfaction: roles of emotion, relationship quality, and self-esteem. Personality and Social Psychology Bulletin, 29, 1596-1608. doi:10.1177/0146167203255986

Kanning, M. and Schlicht, W. (2008). A bio-psycho-social model of successful aging as shown through the variable "physical activity". European Review of Aging and Physical Activity, 5, 79-87. doi:10.1007/s11556-008-0035-4

Litwin, H. and Shiovitz-Ezra, S. (2006). The association between activity and wellbeing in later life: what really matters? Ageing and Society, 26, 225. doi: $10.1017 / \mathrm{S} 0144686 \mathrm{X} 05004538$

Litwin, H. and Stoeckel, K. J. (2013). Social networks and subjective wellbeing among older Europeans: does age make a difference? Ageing and Society, 33, 1263-1281.

Lucas, R. E. and Fujita, F. (2000). Factors influencing the relation between extraversion and pleasant affect. Fournal of Personality and Social Psychology, 79, 1039-1056. doi:10.1037/0022-3514.79.6.1039

Martin, P. and Martin, M. (2002). Proximal and distal influences on development: the model of developmental adaptation. Developmental Review, 22, 78-96. doi:10.1006/drev.2001.0538.

Ní Mhaoláin, A. M. et al. (2012). Subjective well-being amongst community-dwelling elders: what determines satisfaction with life? Findings from the Dublin healthy 
aging study. International Psychogeriatrics, 24, 316-323. doi: $10.1017 / \mathrm{S} 104161021100136$

Otero, J. M., Luengo, A., Romero, E., Gómez, J. A. and Castro, C. (1998). Psicología de Personalidad. Manual de Prácticas [Personality Psychology. Practice Manual]. Barcelona: Ariel Practicum

Ozer, D. J. and Benet-Martínez, V. (2006). Personality and the prediction of consequential outcomes. Annual Review of Psychology, 57, 401-421. doi:10.1146/annurev.psych.57.102904.190127

Peterson, R. A. (1994). A meta-analysis of Cronbach's coefficient alpha. Fournal of Consumer Research, 21, 381-391.

Pons, D., Atienza, F. L., Balaguer, I. and García-Merita, M. (2000). Satisfaction with life scale: analysis of factorial invariance for adolescents and elderly persons. Perceptual and Motor Skills, 91, 62-68. doi:10.2466/pms.2000.91.1.62

Revilla-Ahumada, L., Luna del Castillo, J., Bailón Muñoz, E. and Medina Moruno, I. (2005). Validation of the MOS social support questionnaire in primary care [Validación del cuestionario MOS de apoyo social en atención primaria]. Medicina de Familia, 6, 10-18.

Ringle, C. M., Wende, S. and Becker, J. M. (2015). SmartPLS 3. Bönningstedt: SmartPLS. Available at: http://www.smartpls.com

Robb, C., Small, B. and Haley, W. (2008). Gender differences in coping with functional disability in older married couples: the role of personality and social resources. Aging and Mental Health, 12, 423-433. doi:10.1080/13607860802224326

Robinson, J. P., Shaver, P. R. and Wrightsman, L. S. (1991). Criteria for scale selection and evaluation. In J. P. Robinson, P. R. Shaver and L. S. Wrightsman (eds.), Measures of Personality and Social Psychological Attitudes (pp. 1-16). San Diego, CA: Academic Press.

Rowe, J. W. and Kahn, R. L. (1997). Successful aging. The Gerontologist, 37, 433-440. doi:10.1093/geront/37.4.433

Rowe, J. W. and Kahn, R. L. (2015). Successful aging 2.0: conceptual expansions for the 21 st century. Fournals of
Gerontology, Series B: Psychological Sciences and Social Sciences, 70, 593-596. doi:10.1093/geronb/gbv025

Scheier, M. F., Carver, C. S. and Bridges, M. W. (1994). Distinguishing optimism from neuroticism (and trait anxiety, self-mastery, and self-esteem): a re-evaluation of the life orientation test. Fournal of Personality and Social Psychology, 67, 1063-1078.

Schimmack, U., Radhakrishnan, P., Oishi, S., Dzokoto, V. and Ahadi, S. (2002). Culture, personality, and subjective well-being: integrating process models of life satisfaction. Fournal of Personality and Social Psychology, 82, 582-593. doi:10.1037/0022-3514.82.4.582

Schöllgen, I., Huxhold, O., Schüz, B. and Tesch-Römer, C. (2011). Resources for health: differential effects of optimistic self-beliefs and social support according to socioeconomic status. Health Psychology, 30, 326-335.

Sherbourne, C. D. and Stewart, A. L. (1991). The MOS social support survey. Social Science \& Medicine, 32, 705-714. doi:10.1016/0277-9536(91)90150-B

von Faber, M. et al. (2001). Successful aging in the oldest old: who can be characterized as successfully aged? Archives of Internal Medicine, 161, 2694-2700. doi:10.1001/archinte.161.22.2694

Windsor, T. D., Fiori, K. L. and Crisp, D. A. (2012). Personal and neighborhood resources, future time perspective, and social relations in middle and older adulthood. The fournals of Gerontology Series B: Psychological Sciences and Social Sciences, 67, 423-431. doi:10.1093/geronb/gbr117

Woods, B. and Windle, G. (2008). Personality in later life: the effects of aging on personality. In R. Jacoby, C. Oppenheimer and A. Thomas (eds.), Old Age Psychiatry (pp. 591-604). Oxford, NY, NY: Oxford University Press.

Zarit, S. H. (2009). A good old age: theories of mental health and ageing. In V. L. Bengtson D. N. Gans M. Putney and M. Silverstein, (eds.), Handbook of Theories of Aging (2nd ed., pp. 675-691). New York, USA: Springer. 